\title{
Prevalence of Opportunistic Intestinal Protozoan Infection Among HIVIAIDS Patients in Jalingo Metropolis
}

\author{
Onyeuku Okechukwu Chinwe ${ }^{1,}$, Elkanah Obadiah Sambo ${ }^{2}$, Obiorah Sylvester Chibuzor $^{3}$, \\ Elkanah Deborah Sambo ${ }^{2}$, Egeonu Stephen Ugoeze ${ }^{3}$ \\ ${ }^{1}$ Department of Laboratory Services, Taraba State Specialist Hospital, Jalingo, Nigeria \\ ${ }^{2}$ Department of Biological Sciences, Taraba State University, Jalingo, Nigeria \\ ${ }^{3}$ Department of Laboratory Services, Federal Medical Centre, Jalingo, Nigeria
}

Email address:

okechukwuonyeuku66@gmail.com (O. O. Chinwe)

${ }^{*}$ Corresponding author

\section{To cite this article:}

Onyeuku Okechukwu Chinwe, Elkanah Obadiah Sambo, Obiorah Sylvester Chibuzor, Elkanah Deborah Sambo, Egeonu Stephen Ugoeze. Prevalence of Opportunistic Intestinal Protozoan Infection Among Hiv/Aids Patients in Jalingo Metropolis. Biomedical Sciences. Vol. 6, No. 3, 2020, pp. 74-78. doi: 10.11648/j.bs.20200603.16

Received: July 18, 2020; Accepted: August 19, 2020; Published: September 19, 2020

\begin{abstract}
Opportunistic protozoans parasitic infection occur frequently in individuals with weakened immune system including people with HIV/AIDS. The study sought to determine the prevalence of opportunistic intestinal protozoan infection in HIV/AIDS patients in Jalingo metropolis. The procedure of wet mount technique and faecal concentration techniques processed the faeces collected. The $\mathrm{CD}^{4+}$ count of patients were determined using the Partee Cyflow Counter, which determines the percentage of $\mathrm{CD}^{4+}$ cells of individuals. A total of eight hundred and fifty (850) faecal samples were collected from sero-positive and sero-negative HIV/AIDS persons in Jalingo metropolis. Out of the 850 subjects 650 (76.47\%) were sero-positive while 200 (23.53\%) were sero-negative (Control). The sero-positive subjects showed higher prevalence of 118 $(18.15 \%)$ of opportunistic parasitic protozoan infection according to the following hospital locations: Government House, 12 (25.71\%); Ummah Clinic, 8 (21.82\%); Taraba State Specialist Hospital, 50 (18.18\%) and Federal Medical Centre, 38 (15.20\%). The prevalence was higher among female positives, $68(19.60 \%)$ than the male, $50(16.50 \%)$ with no significant difference $(p>0.05)$. The infection based on age groups revealed that the age group 10-15 years had the highest prevalence of 27 (48.21\%) while the age group 41-45 years had the least prevalence of $2(2.63 \%)$. Subjects involved in farming had higher prevalence 30 $(46.15 \%)$ while the least was found among those of trading/business, 33 (13.86\%) with no significant difference in infection ( $>0.05)$. C. parvum had the highest prevalence, $46(24.46 \%)$ among the sero-positive individuals while $E$. coli the highest among sero-negative, $9(60.00 \%)$. It is recommended that clinicians caring for HIV/AIDS patients should request for routine stool examination for the specific diagnosis of opportunistic intestinal parasites infections.
\end{abstract}

Keywords: Protozoans, Infections, HIV/AIDS, Patients, Opportunistic

\section{Introduction}

Opportunistic protozoans occur frequently in individuals with weakened immune system including people with HIV/AIDS. The predisposing factors to getting opportunistic intestinal protozoan parasites include living in/or visiting areas known to have these parasites, international travels, poor sanitation (for both food and water), exposure to child and institutional care center, having a weekend immune system and HIV/AIDS predispose individual to infection [1].
Opportunistic intestinal protozoans are among the major contributor to the global intestinal parasite load. In different parts of the world a wide variety of intestinal parasites are prevalent. Entamoeba spp, Toxoplasma gondii, Cyclospora, Giardia lamblia and Cryptosporidium are among the major contributors to the global intestinal parasitic disease body.

The Human Immunodeficiency Virus (HIV) is a sexually transmitted disease. HIV can also be spread via blood and blood products most commonly with shared contaminated needles used by person engaging in intravenous drugs' use [2]. 
The Human immune deficiency virus (HIV) is a virus that attacks the immune system which is the body's natural defense against illnesses. A person infected with HIV finds it more difficult to fight infectious disease. The viruses destroy white cell called T-helper cells, replicating inside them. T-helper cells are also known as $\mathrm{CD}^{4+}$ cells. There are two types of HIV: type -1 is the most common type and it is found worldwide. HIV-2 is found mostly in West Africa and in some cases in India and Europe [3]. HIV infection causes a progressive destruction of the cell mediated (CMI) system by eliminating $\mathrm{CD}^{+}$or T-helper lymphocytes. Decreased immunity leads to opportunistic infections and certain cancers [3].

HIV/AIDS is a scourge in sub-Sahara Africa despite the ameliorating effects of Highly Active Antiretroviral Therapy (HAART). The prevalence of HIV/AIDS in Taraba State is $10.5 \%$ [4]. Opportunistic intestinal protozoan infections pose a great danger to the HIV/AIDS patients with complications. There is a paucity of information on the role of opportunistic protozoan infections among HIV/AIDS patients in the study area hence, this study determined the prevalence of opportunistic intestinal protozoan infection in HIV/AIDS patients in Jalingo metropolis.

\section{Materials and Methods}

\subsection{Study Area}

Jalingo is a city in North-Eastern Nigeria. It is the capital of Taraba State and the headquarters of Jalingo Local Government. The Local Government borders Ardo-Kola in the south, Lau Local Government in the North, Yorro Local Government to the East. Wards within Jalingo are Barade, Mayo-Gwoi, Turaki A, Turaki B, Abbare Yelwa, Kachalla sembe, Kona, Majidadi, Sarkin Dawaki and Sintali. Jalingo Local Government is located between latitude $8^{\circ} 89^{\prime} \mathrm{N}$, longitude $11^{\circ} 38^{\prime} \mathrm{E}$. The majority of inhabitants of the L. G. A live in rural communities with farming and civil service as their major occupation. The mean annual rainfall of the area is $1305 \mathrm{~mm}$ with guinea savannah as bioecological structure.

\subsection{Ethical Permission}

Ethical permission was sought and obtained from the various hospital managements before the collection of samples from the patients. Prior to this, the study was approved by the ethical committee of Postgraduate unit of Biological Science Department, Taraba State University, Jalingo.

\subsection{Sample Collection}

The study design for this work is a cross sectional descriptive study. A total of 650 stool samples were collected from both male and female HIV/AIDS patients and 200 stool samples were also collected from non-HIV/AIDS patients to serve as control. Permission of the parents, hospital and patients were sought for, before the commencement of the study. Each patient was provided with a pre-labelled $60 \mathrm{ml}$ universal sample bottle for stool collection. The patients were instructed on how to collect the sample. The samples were preserved into a flask and transported to the laboratory Department of Taraba State Specialist hospital Jalingo, for analysis.

\subsection{Questionnaires'Administration}

A questionnaire relevant to the study was issued to each patient to obtain information on: age, sex, level of education, occupation of parents, and history of previous health status.

\subsection{Microscopic Examination of the Stool}

Two methods of examining the stool were employed as described in the wet mount technique and the concentration technique [5].

The procedure of wet mount technique is as follows: a microscope slide was obtained and one drop of normal saline was placed on one end of the slide. A drop of iodine was placed on the other end to incorporate into the faeces-saline mixture after an initial examination for motile trophozoites. A small amount of the stool was introduced to the drop or saline and another similar specimen into dilute iodine.

Faecal concentration was processed by the sedimentation method. This increased the probability of finding parasites and their ova when low numbers are present in the stool specimen. This is a routine technique and is often used in conjunction with a floatation method that is particularly valuable in detecting ova of parasites but the ethyl acetate method is most commonly used for concentrating eggs and cysts. A single concentrated sample from an infected patient is sometimes adequate for detecting helminths (worms). It is often necessary to utilize several specimen in order to detect protozoan organisms due to the difficulty in finding the stages that are somewhat identified.

\subsection{Statistical Analysis}

Microsoft Excel and SPSS were used to analyze data. Frequency distribution table, percentages, prevalence of infection Attributed to intestinal protozoans in HIV/AIDS patients were estimated. Also, Chi-square $\left(\chi^{2}\right)$ was used to determine associations between infection and various demographic data obtained. The level of significance was set at $\mathrm{P} \leq 0.05$.

\section{Results}

A total of eight hundred and fifty (850) faecal samples were collected from sero-positive and sero-negative HIV/AIDS persons in Jalingo metropolis. Out of the 850 subjects 650 $(76.47 \%)$ were sero-positive for HIV/AIDS while 200 $(23.53 \%)$ were sero-negative (Control). The sero-positive subject showed higher prevalence of 118 (18.15\%) of opportunistic parasitic infection according to the following hospital locations; Govt. House 12 (25.71\%), Ummah Clinic 8 (21.82\%) Taraba State Specialist Hospital, 50 (18.18\%) and Federal Medical Centre, 38 (15.20\%) in decreasing order of prevalence. Sero-negative subjects on the other hand showed lower prevalence $15(7.50 \%)$. In comparison to the HIV positive subjects in this order; Taraba State Specialist Hospital, $6(8.00 \%)$; Federal Medical center (FMC), 6 (8.00\%); Govt. 
House, 2 (6.67\%) and Ummah Clinic 2 (6.67\% respectively (Table 1). Chi-square analysis revealed that there is no significant association between the occurence of opportunistic intestinal protozoan infection among HIV sero-positive and HIV sero-negative subjects in the selected Health centres in Jalingo $\left(\chi^{2}=14.06 \mathrm{p} \geq 0.05\right)$.

Table 1. Prevalence of Opportunistic Intestinal Protozoan Infection among HIV sero-positive and HIV sero-negative subjects in Jalingo based on Health centres.

\begin{tabular}{|c|c|c|c|c|c|c|}
\hline \multicolumn{4}{|l|}{ HIV Sero-positive } & \multicolumn{3}{|c|}{ HIV Sero-negative } \\
\hline Total & No. Examined & No. infected (\%) & No. Examined & No infected (\%) & No. Examined & No. infected (\%) \\
\hline \multicolumn{7}{|l|}{ Health Location } \\
\hline TSSH JAL. & 275 & $50(18.18)$ & 75 & $6(8.00)$ & 350 & $56(16.00)$ \\
\hline FMC JAL. & 250 & $38(15.12)$ & 50 & $4(8.00)$ & 300 & $42(14.00)$ \\
\hline GOVT. HOUSE & 70 & $12(25.71)$ & 30 & $2(6067)$ & 100 & $20(20.00)$ \\
\hline UMMAH CLINIC & 55 & $8(21.82)$ & 45 & $3(6.67)$ & 100 & $15(15.00)$ \\
\hline TOTAL & 650 & $118(18.15)$ & 200 & $15(7.50)$ & 850 & $133(15.65)$ \\
\hline
\end{tabular}

Key $\mathrm{GHC}=$ Govt. House clinic.

$\mathrm{UMC}=$ Ummah Clinic.

TSSH JAL. $=$ Taraba State Specialist Hospital Jalingo.

$\mathrm{FMC}=$ Federal Medical Centre.

Table 2 shows the age and gender specific prevalence of Opportunistic intestinal protozoan among HIV/AIDS in positive patients which reveals that, the prevalence was higher among female positives $68(19.60 \%)$ than the male 50 $(16.50 \%)$. There was no statistically significant difference in infection among sexes $(p<0.05)$. On the other hand, the occurrence of intestinal protozoan Infection based on age group revealed that the age group between 10-15 years had the highest prevalence of 27 (48.21\%), followed by 26-30 years age group $18(28.13 \%)$ the least prevalence of $2(2.63 \%)$ was recorded among 41-45 years in a decreasing order respectively. The Chi square analysis revealed that there is significant difference in infetions among age groups and the occurrence of Opportunistic Intestinal protozoan infection among HIV sero-positive and HIV sero-negative subject $(p \leq 0.05)$.

Table 2. Age and Gender Specific Infections of Intestinal protozoan in HIV Subject in study area.

\begin{tabular}{|c|c|c|c|c|c|c|}
\hline \multirow{2}{*}{ Age (Years) } & \multicolumn{2}{|l|}{ Male } & \multicolumn{2}{|l|}{ Female } & \multicolumn{2}{|l|}{ Total } \\
\hline & No. Exam & No. inf (\%) & No. Exam & No. inf (\%) & No. exam & No. inf (\%) \\
\hline $10-15$ & 33 & $12(36.36)$ & 23 & $15(65.21)$ & 56 & $27(48.21)$ \\
\hline $16-20$ & 33 & $7(21.21)$ & 42 & $11(26.19)$ & 75 & $18(24.0)$ \\
\hline $21-25$ & 29 & $7(24.13)$ & 42 & $8(19.04)$ & 71 & $15(21.13)$ \\
\hline $26-30$ & 34 & $11(32.35)$ & 30 & $7(23.33)$ & 64 & $18(28.13)$ \\
\hline $31-35$ & 47 & $4(8.51)$ & 54 & $11(20.37)$ & 101 & $15(14.85)$ \\
\hline $36-40$ & 41 & $3(7.32)$ & 54 & $6(11.11)$ & 95 & $9(9.47)$ \\
\hline $46-50$ & 32 & $2(6.25)$ & 40 & $4(10.0)$ & 72 & $6(8.33)$ \\
\hline 51 above & 21 & $3(14.28)$ & 19 & $5(26.32)$ & 40 & $8(20.00)$ \\
\hline TOTAL & 303 & $50(16.50)$ & 347 & $68(19.60)$ & 650 & $118(18.15)$ \\
\hline
\end{tabular}

The prevalence of opportunistic intestinal protozoan infection in relation to occupation among HIV positive subjects in Jalingo Metropolis showed that farmers 30 $(40.15 \%)$ had the highest prevalence followed by students 29 $(16.20 \%)$ while the least were traders $33(13.86 \%)$. There was statistically significant difference $(\mathrm{p} \leq 0.05)$ in prevalence of protozoan infection among HIV positive subjects involved in different occupations (Table 3).

Table 3. Prevalence of opportunistic intestinal protozoan infection in relation to occupation among HIV patients in Jalingo Metropolis.

\begin{tabular}{lll}
\hline Occupation & No. Examined & No. Infected (\%) \\
\hline Farming & 65 & $30(46.15)$ \\
Civil service & 168 & $26(15.48)$ \\
Students & 179 & $29(16.20)$ \\
Trading/business & 238 & $33(13.86)$ \\
Total & 650 & $118(18.15)$ \\
\hline
\end{tabular}

Table 4 showed the prevalence of intestinal protozoan species in HIV/AIDS subjects (sero-positive) and non-HIV/AIDS (sero-negative) subjects. The analysis revealed four (4) species of the intestinal protozoon parasites which are: Cryptosporidium spp, 46 (7.10\%); Entamoeba coli, 40 (6.15\%); Entamoeba histolytica, 30 (5.0\%) and Giardia lamblia, 2 (0.2\%). However, in the sero-negative (Non-HIVsubjects) Entamoeba coli, 9 (4.5\%) occurrence was found to be predominant. The overall occurrence of intestinal protozoan parasites in both sero-positive and sero-negative subjects was $118(18.15 \%)$. There was statistically significant difference $\left(\chi^{2}=12.23, \mathrm{p} \leq 0.05\right)$ between Sero-positive and sero-negative patients in acquiring opportunistic intestinal protozoan infections.

Table 4. Frequency of Occurrence of Opportunistic Intestinal Protozoan species in sero-positive and sero-negative HIV subject in Jalingo Metropolis.

\begin{tabular}{|c|c|c|c|}
\hline \multicolumn{4}{|c|}{ Opportunistic Intestinal Protozoans (\%) } \\
\hline \multicolumn{2}{|c|}{ HIVsero-positive } & \multicolumn{2}{|c|}{ HIV sero-negative Total } \\
\hline G. lamblia & $2(1.06)$ & 0.00 & $2(0.98)$ \\
\hline E. histolytica & $30(15.95)$ & $6(40.00)$ & $36(17.73)$ \\
\hline E. coli & $40(21.27)$ & $9(60.00)$ & $49(24.13)$ \\
\hline C. parvum & $46(24.46)$ & 0.00 & $46(22.66)$ \\
\hline Total & 188 & 15 & 203 \\
\hline
\end{tabular}




\section{Discussion}

HIV/AIDS is a leading public health challenge in Africa especially in Nigeria which has huge population. Prevalence of opportunistic intestinal parasites are common features in HIV sero-positive individual where majority of AIDS patients die of AIDS related infections including those due to intestinal protozoan parasites rather than the HIV infection itself as it is revealed in this present study. HIV virus suppresses the immunity of individuals and results in the reduced immune response against other pathogens. Therefore, HIV infected subjects become at high risk of acquiring intestinal protozoan infection. The result from this study showed a moderate prevalence (18.15\%) of intestinal parasitic infections in the study area. Amoebiasis, Giardiasis and Cryptosporodiasis are among the most commonly diagnosed intestinal parasites from the study participants. This prevalence was lower in comparison to the $44.8 \%$ and $47.5 \%$ reported in Ethiopia and DR Congo [6, 7].

In this study, Entamoeba coli and Entamoeba histolytica Infections were found to be highly prevalent intestinal protozoan parasites along with Giardia lamblia. This is probably due to the shortage of safe drinking water in most part of Jalingo metropolis. The occurrence of these parasites among HIV/AIDS patients is similar to the research work carried out elsewhere in Africa [7].

Intestinal protozoan infection was found highest in age groups between 10-15 years old. It was this age category that HIV cases and intestinal parasites were a common occurrence in the population studied. However, the high infection rate was also observed among the age groups: $16-30$ years and 51 years. Nonetheless, the difference in the observed and prevalence was not statistically significant. The incidence could largely be due to the lack of safe, potable drinking water, poor hygienic and sanitary conditions. It is important to note that the prevalence $(90 \%)$ observed among HIV-infected patients is in contrast with the work of Akinbo et al. [8].

The result of our investigation in this study shows that, there was no significant difference $(\mathrm{P}>0.05)$ in prevalence of infection between male and female subjects. However infection was found higher in females $(19.60 \%)$ than male $(16.50 \%)$ examined. This is probably due to the fact that females are usually, exposed to intestinal protozoan parasites compared to their male counterparts based on occupational ground such as engagement in numerous household chores constant contact with contaminated water and soil as observed also in previous report of Teklay et al. [9].

Intestinal protozoan infections in HIV/AIDS subject require a careful study in a developing world where poor nutrition is associated with poor hygiene and several tropical diseases. The parasite detected in this study for HIV subjects include Cryptosporidium species (7.10\%), Entamoeba coli (6.15\%), Entamoeba histolytica (5\%) and Giardia lamblia (2\%). Cryptosporidium species was found to be significantly higher in HIV/AIDS subject than in the control samples. This could be transmitted to relatively low immure status of subject with HIV/AIDS. This is in agreement with the research carried out in Ethiopia [10, 11]. Cryptosporidium sp has been reported in other countries within Africa [12-15].

\section{Conclusion}

This study has demonstrated the occurrence of opportunistic intestinal protozoan parasite in sero-positive HIV/AIDS subjects is $(18.15 \%)$ in study area. The predominant opportunistic intestinal protozoan observed were Cryptosportdium spp, Giadia lamblia, Entamoeba coli and Entamoeba histolytica. Entamoeba coli and Entamoeba histolytica occurred in both groups (Sero-positive and sero-negative subjects). The high prevalence of Entamoeba coli suggests a potential contamination of drinking water in the catchment areas of our study. It is recommended that clinicians caring for HIV/AIDS patients should request for routine stool examination for the specific diagnosis of opportunistic intestinal parasites.

\section{References}

[1] Obateru, O. A., Bojuwoye, B. J., Olokoba, A. B., Fadeyi, A. F., Olokoba, L. B. Prevalence of intestinal parasites in newly diagnosed HIV/AIDS patients in Ilorin, Nigeria. Alexandria Journal of Medicine, 2017; 53 (2): 111-116.

[2] Ryan, K. J. and Ray, C. G. Sherris Medical Microbiology. 4th ed. McGraw Hill, 2004. pp. 733-738.

[3] Gupta, K., Bala, M., Deb, M., Muralidhar, S. and Sharma, D. $\mathrm{K}$. Prevalence of intestinal parasitic infections in HIV -infected individuals and their relationship with immune status. Indian Journal of Medical Microbiology, 2013; 31: 161-165.

[4] National Agency for the Control of AIDS. Report on prevalence of HIV/AIDS in Nigeria-National Agency For The Control of HIV/AIDS, 2015; Pg 1129-1178.

[5] Cheesbrough M. District laboratory practice in tropical countries. New York-Cambridge Press. Part1, $2^{\text {nd }}$ Edition, $2012 ; 249-258$.

[6] Alemu G, Alelign D, Abossie A. Prevalence of Opportunistic Intestinal Parasites and Associated Factors among HIV Patients while Receiving ART at Arba Minch Hospital in Southern Ethiopia: A Cross-sectional Study. Ethiop J Health Sci. 2018; 28 (2): 147-156. doi: 10.4314/ejhs.v28i2.6.

[7] Barcelos Natane Barbosa, Silva Lorena de Freitas e, Dias Regyane Ferreira Guimarães, Menezes Filho Hélio Ranes de, Rodrigues Rosângela Maria. Opportunistic and non-opportunistic intestinal parasites in HIV/ AIDS patients in relation to their clinical and epidemiological status in a specialized medical service in Goiás, Brazil. Rev. Inst. Med. trop. S. Paulo [Internet]. 2018 [cited 2020 Aug 18]; 60: e13. Available from: http://www.scielo.br/scielo.php?script=sci_arttext\&pid=S0036 $-46652018005000206 \& \operatorname{lng}=$ en. Epub Mar 08, 2018. https: //doi.org/10.1590/s1678-9946201860013.

[8] Akinbo F O, Anate P J, Akinbo D B, Omoregie R, Okoosi S, Abdulsalami A, Isah B. Risk factors of intestinal parasitic infections among human immunodeficiency virus-infected patients on highly active antiretroviral therapy. Port Harcourt Med J, 2017; 11: 15-20. 
[9] Teklay, G., Haftom, K., Abebaw, A. G. Intestinal parasites among HIV/AIDS patients attending University of Gondar Hospital, northwest Ethiopia. Ethiop. J. Health Dev. 2019; 33 (2): 64-72.

[10] Bokore A, Korme B, Bayisa G. Determinants of anti-retroviral regimen changes among HIV/AIDS patients of east and west Wollega zone health institutions, Oromia region, west Ethiopia: a cross-sectional study. BMC Pharmacol Toxicol 2018; 19 (1): 28.

[11] Gebre B, Alemayehu T, Girma M, Ayalew F, Tadesse BT, Shemelis T. Cryptosporidiosis And Other Intestinal Parasitic Infections And Concomitant Threats Among HIV-Infected Children In Southern Ethiopia Receiving First-Line Antiretroviral Therapy. HIV AIDS (Auckl). 2019; 11: 299-306. Published 2019 Nov 15. doi: 10.2147/HIV.S215417.

[12] Awofala AA, Ogundele OE. HIV epidemiology in Nigeria. Saudi J Biol Sci. 2016. doi: 10.1016/j.sjbs.2016.03.006.
[13] Jegede FE, Oyeyi TI, Abdulrahman SA, Mbah HA, Badru T, Agbakwuru $\mathrm{C}$ et al. Effect of HIV and malaria parasites co-infection on immune-hematological profiles among patients attending anti-retroviral treatment (ART) clinic in Infectious Disease Hospital Kano, Nigeria. PloS One. 2017; 12 (3): e0174233.

[14] Wang ZD, Liu Q, Liu HH. Prevalence of Cryptosporidium, microsporidia and Isospora infection in HIV-infected people: a global systematic review and meta-analysis. Parasites \& Vectors. 2018 Jan; $11 \quad$ (1): 28. DOI: 10.1186/s13071-017-2558-x.

[15] Ahmadpour E, Safarpour H, Xiao L, Zarean M, Hatam-Nahavandi K, Barac A, Picot S, Rahimi MT, Rubino S, Mahami-Oskouei M, Spotin A, Nami S, Baghi HB. Cryptosporidiosis in HIV-positive patients and related risk factors: A systematic review and meta-analysis. Parasite, 2020; 27. https://doi.org/10.1051/parasite/2020025. 